Supplement of Geosci. Model Dev., 12, 5291-5300, 2019

https://doi.org/10.5194/gmd-12-5291-2019-supplement

(c) Author(s) 2019. This work is distributed under

the Creative Commons Attribution 4.0 License.

(c) (1)

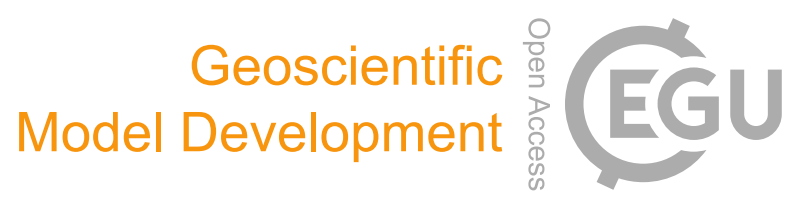

Supplement of

\title{
Ground subsidence effects on simulating dynamic high-latitude surface inundation under permafrost thaw using CLM5
}

\author{
Altug Ekici et al. \\ Correspondence to: Altug Ekici (ekici@ climate.unibe.ch)
}

The copyright of individual parts of the supplement might differ from the CC BY 4.0 License. 


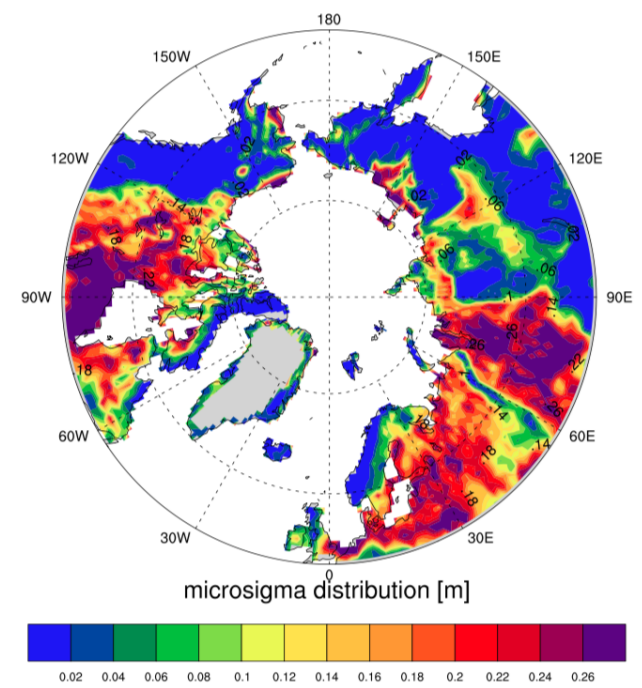

Fig. S1: High latitude $\left(>50^{\circ} \mathrm{N}\right)$ map of default microsigma distribution.

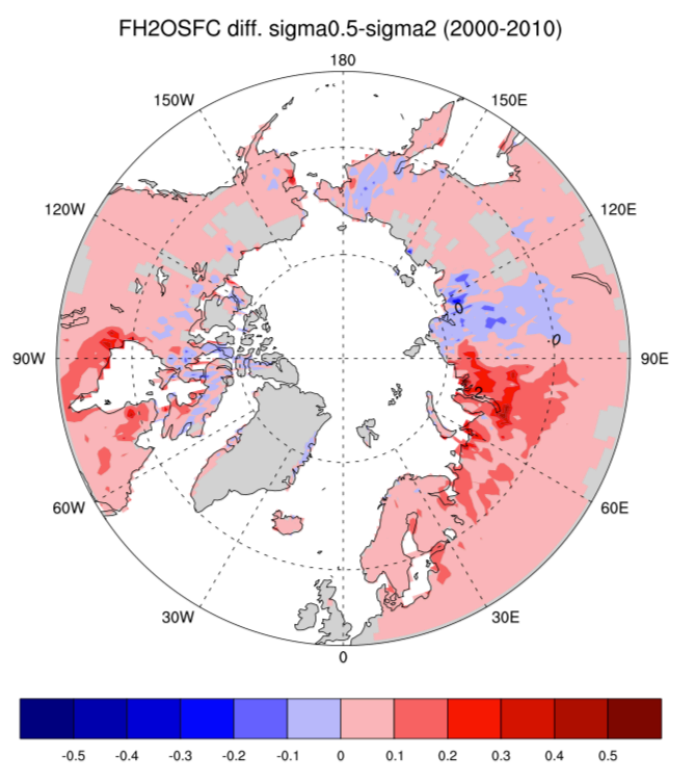

Fig. S2: Fh2osfc difference between Sigma-0.5 and Sigma-2 experiments. 
Spin up timeseries of soil variables
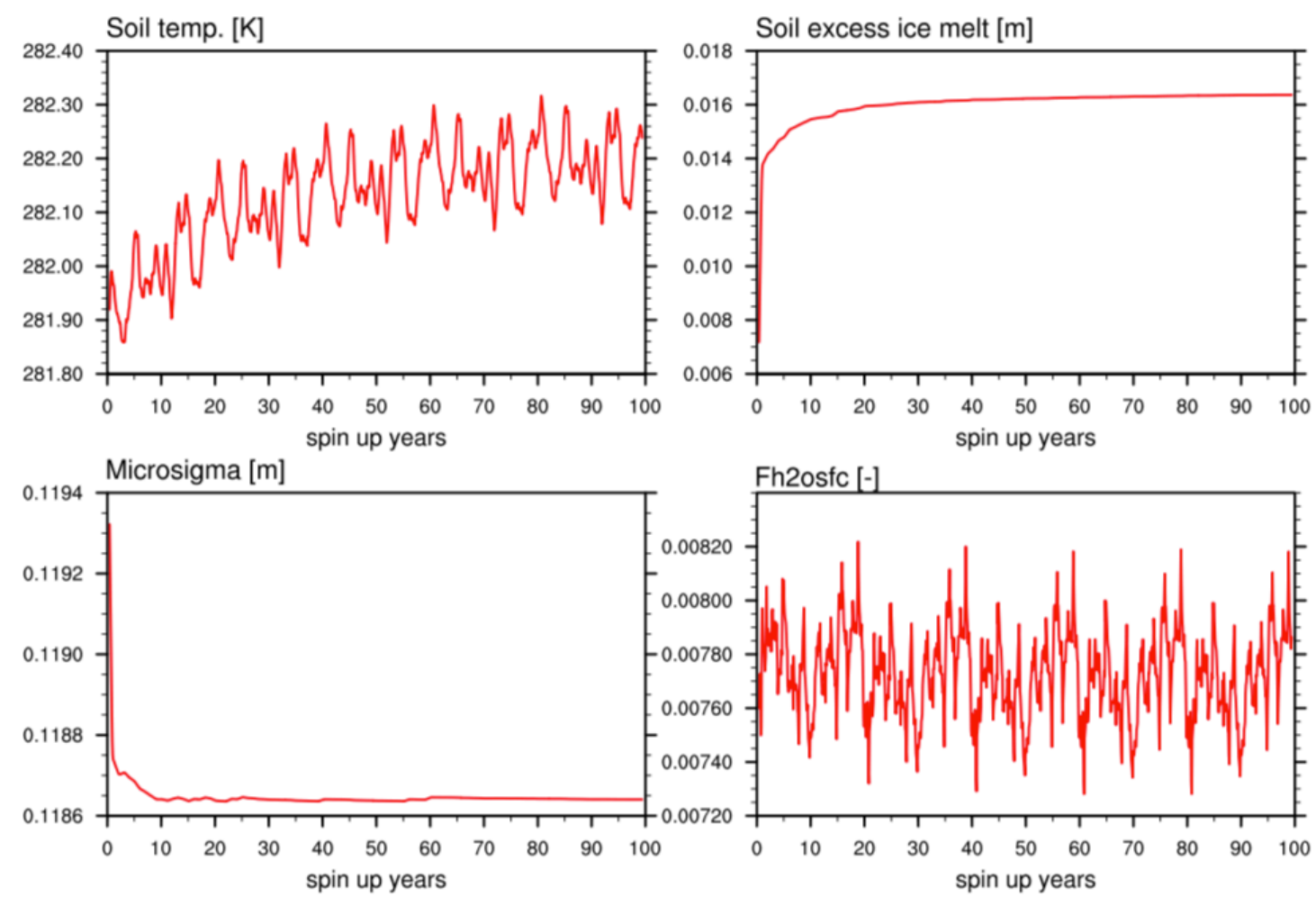

Fh2osfc [-]

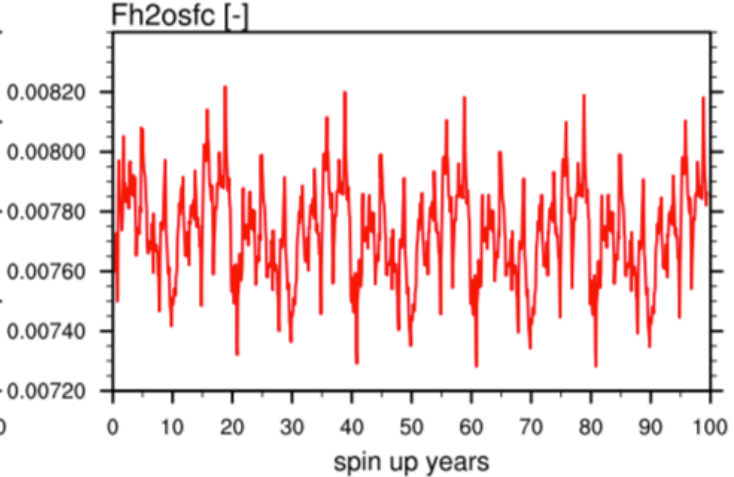

Fig. S3: 100 year spin up timeseries of spatially averaged soil physical variables related to the new parameterization.

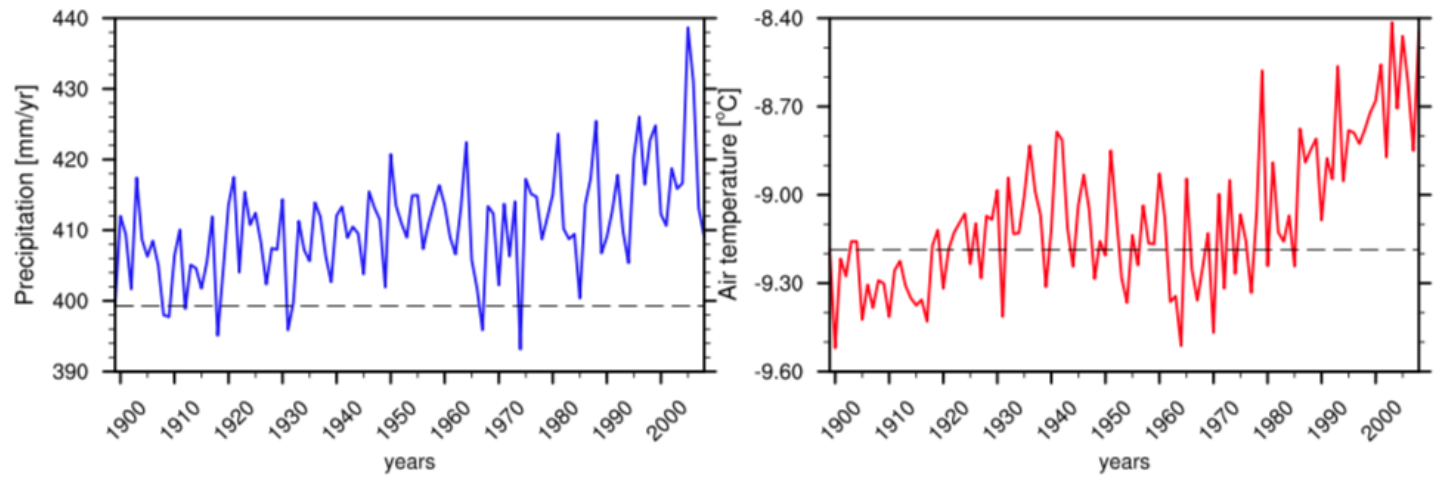

Fig. S4: Timeseries of high latitude $\left(>50^{\circ} \mathrm{N}\right.$ average-land only) CRUNCEP precipitation and air temperature forcing for the period 1900-2010. Dotted lines show 1900 value. 